https://doi.org/10.30910/turkjans.680030

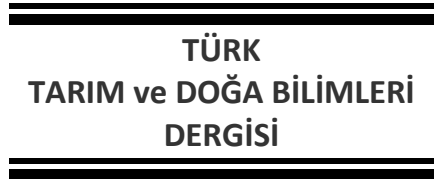

\title{
Araştırma Makalesi \\ MEDALUS Yöntemi Kullanılarak Karacabey Tarım İşletmesi Toprak Kalite İndeksinin Değerlendirilmesi
}

\author{
Timuçin EVEREST ${ }^{1 *}$, Ali SUNGUR², Hasan ÖZCAN² \\ ${ }^{1}$ Çanakkale Onsekiz Mart Üniversitesi, Lapseki Meslek Yüksekokulu, Çanakkale \\ ${ }^{2}$ Çanakkale Onsekiz Mart Üniversitesi, Ziraat Fakültesi Toprak Bilimi ve Bitki Besleme Bölümü, Çanakkale \\ *Sorumlu yazar: timucineverest@comu.edu.tr
}

Geliş Tarihi: 25.10 .2019

Düzeltme Geliş Tarihi: 09.12.2019

Kabul Tarihi: 09.12.2019

\section{Özet}

Bu çalışma, Bursa ilinin Karacabey ilçesinde bulunan Karacabey Tarım Işletmesi toprak kalite indeksinin (TKi) belirlenmesi amacıyla gerçekleştirilmiştir. Akdeniz ülkelerinde çölleşmeye duyarlı arazilerin belirlenmesi ve hassas alanların ortaya konması için Avrupa Birliği tarafından uygulanan Akdeniz Çölleşme ve Arazi Kullanımı (MEDALUS) yaklaşımı çalışma alanı arazileri için uygulanmışıı. Çalışmada arazi karakteristiklerinin ortaya konması için (tekstür, drenaj, derinlik, ana materyal) Tarım İşletmeleri Genel Müdürlüğü (TiGEM) tarafından üretilmiş detaylı toprak etüt ve haritalama raporu ile NASA (National Aeronautical Space Administration-Ulusal Havacılık Dairesi) web sayfasından indirilen $30 \mathrm{~m}$ mekânsal çözünürlüğe sahip DEM (Digital Elevation ModelSayısal Yükseklik Modeli) verisi kullanılmıştır. Her bir haritalama biriminde bulunan parametreler yöntemde öngörülen skor cetvelleri kullanılarak skorlanmışıı. Yapılan analizler ve hesaplamalar sonucunda işletme arazisinin MEDALUS yöntemine göre toprakların çölleşme riski yönünden kalite özellikleri \% 8.28'i iyi, \% 49.17'si orta ve \% 42.55 'i zayıf olarak sınıflandııılmıştır. Küresel ııınmanın ve iklim değişikliğinin yaşandığı günümüzde bu tür yöntemler kullanılarak arazilerin hassasiyeti ve degradasyona duyarlıık süreçleri hakkında projeksiyonlar oluşturmak hem geliştirilecek politikalar hem de sürdürülebilir bir arazi yönetimi açısından önemli bilgiler sunabilecektir.

Anahtar kelimeler: Arazi degradasyonu, arazi kalitesi, MEDALUS, çölleşme, iklim değişikliği.

\section{Evaluation of Soil Quality Index of Karacabey State Farm Using MEDALUS Methodology}

\begin{abstract}
The aim of this study was to determine the soil quality index (SQI) of Karacabey State Farm in Karacabey district of Bursa province. In this study, the Mediterranean Desertification and Land Use (MEDALUS) approach applied by the European Union to determine sensitive areas in Mediterranean countries was used in this study area. In the study, land characteristics (soil texture, drainage, depth, parent material) were obtained from soil survey and mapping report which produced by General Directorate of Agricultural Enterprises. Topographic parameters were obtained from Digital Elevation Model (DEM) data that downloaded from NASA (National Aeronautical Space Administration) with $30 \mathrm{~m}$ spatial resolution were used. The parameters which belongs to each mapping unit were scored using the score scales predicted in the method. As a result of the analyzes and calculations, $8.28 \%$ of the study area was classified as high quality, $49.17 \%$ as moderate quality and $42.55 \%$ as low quality according to MEDALUS methodology. In this period of global warming and climate change, it is useful to create projections about the degradation sensitivity of the land by using such methods. By this way, both policy-making and generating information about sustainable land management can be provided.
\end{abstract}

Key words: Land degradation, land quality, MEDALUS, desertification, climate change. 


\section{Giriş}

Doğal kaynakların potansiyellerine uygun olarak kullanılmamaları zaman içerisinde çeşitli düzeylerde degredasyona neden olabilmektedir. Doğal kaynaklar içerisinde yer alan arazilerde meydana gelen degradasyon çok çeşitli nedenlerden kaynaklanabilmektedir. Uygun olmayan amenajman tekniklerinin kullanılması kaynaklı tarımsal kökenli arazi degradasyonu, giderek artarak küresel ölçekte bir sorun haline gelmektedir. Arazi kullanım türlerindeki değişkenlik, mera ve orman alanlarının tahrip edilmesi, uygun olmayan su ve sulama sistemlerinin kullanılması, aşırı otlatma, bilinçsiz ve fazla kimyasal kullanımı, gereksiz tarla trafiği, uygun olmayan ekipmanlarla yapılan toprak işleme, monokültür tarım, biyolojik olarak parçalanamayan kirleticilerin toprağa atılması vb. olumsuz faaliyetler arazilerde degradasyona neden olmaktadır.

Son zamanlarda yarı kurak ekosistemlerde arazi örtüsünde ve peyzajda önemli değişiklikler meydana gelmiştir. Bu değişimin başlıca nedenleri iklimsel koşullar, nüfus artışı arazi gereksinimi olan paydaşlardaki artıştan dolayı tarım alanlarının azalması olarak tanımlanmaktadır (Benabderrahmane ve Chenchouni, 2010; Everest, 2018).

Günümüzde küresel ısınmasın etkileri farklı şekillerde hissedilmektedir. Gelecek yıllarda arazilerin kullanımı ve ürün planlanması konusunda dikkate alınacak en önemli unsurlardan biri arazi karakteristiklerinin yanında iklim koşullarında oluşacak değişkenlikler olarak görülmektedir. iklimsel etmenler ile yaşanan değişiklikler ve arazilerin kuraklık duyarlılıkları değişebilecektir. Arazi kuraklık duyarlılığı ile uyumlu olmayan amenajman tekniklerini uygulanması arazilerde çölleşme risklerini artıracaktır. Çölleşme arazi degradasyonun son evresi olup arazilerdeki biyolojik ve ekonomik kayıpların devamlı bir hal aldığı süreç olarak tanımlanmaktadır (Kosmas ve ark, 1999; Aksoy, 2016). Akdeniz ülkelerinde çölleşmeye duyarları bölgelerin araştırılması ve bu alanlara çözüm bulmak amacıyla 1999 yılında 10 ülkenin katılımıyla 31 gruptan oluşan bir çevre programı oluşturulmuştur. Bu çevre programı içinde önerilen MEDALUS yaklaşımı çölleşmeye hassas alanların belirlenmesini amaçlamaktadır. Bu metedolojide; arazi kullanımı ve iklimin etkisiyle çölleşme riski bulunan duyarlı alanlar ESA indeksi (Environmental Sensitivity Areas) kavramı ile değerlendirilmiştir. ESA indeksini oluşturan bileşenler iklimsel göstergeler, toprak kalitesi, arazi kullanımı ve amenajman faaliyetleridir (Bayramin, 2003; Salvati ve Zitti, 2005). Bu dört parametrenin her biri sınıflandırılır ve her sınıfa bir ağırlık faktörü atanır. Takiben, her dört katman için değerlendirmeler yapılır. Her katman için indeksler hesaplanarak çölleşmeye duyarlı alanlar tanımlanır (Sepehr ve ark. 2007).

Doğal kaynakların mevcut durumlarının belirlenmesi ileride yapılacak projeksiyonlar için önemli bir altlık oluşturmaktadır. Oluşturulan veri tabanlarında Coğrafi Bilgi Sistemi (CBS) ortamında farklı katmanların üretilmesi, bu verilerin karar vericiler tarafından kullanılmasını kolaylaştıracaktır. Literatür incelendiğinde MEDALUS yöntemi kullanılarak toprakların kalite indekslerinin ortaya konduğu çalışmalar bulunmaktadır (Bayramin, 2003; Dengiz ve ark, 2004; Kosmas ve ark., 1999; Sepehr ve ark, 2007; De Paola ve ark., 2013; Contador ve ark, 2009; Ladisa ve ark., 2012; Aksoy, 2016; Lahlaoi ve ark, 2017; Budak ve ark, 2018).

Bu çalışma ile Avrupa Komisyonu tarafından ortaya konan MEDALUS yaklaşımı (Akdeniz Çölleşme ve Arazi Kullanımı) ile Bursa ili sınırları içinde bulunan Karacabey Tarım İşletmesi arazilerinin toprak kalite indekslerinin değerlendirilmesi amaçlanmaktadır.

\section{Materyal ve Yöntem}

Bursa ilinin yaklaşık $60 \mathrm{~km}$ batısında bulunan Karacabey Tarım İşletmesi $40^{\circ} 06^{\prime} 41^{\prime \prime}$ - 40 $10^{\circ}$ '47" kuzey enlemleri ve $28^{\circ} 17^{\prime} 31^{\prime \prime}-28^{\circ} 18^{\prime} 41^{\prime \prime}$ doğu boylamları arasında yer almakta (Şekil 1 ) ve yaklaşık 101525 da alan kaplamaktadır. Marmara ile Ege Denizinin etkisinde kalan araştırma alanının iklimsel özellikleri büyük ölçüde Akdeniz iklim tipine benzerlik göstermektedir (TIGEM, 1988). Karacabey ilçesine uzun yıllar mevsimsel istatistiksel veriler değerlendirildiğinde yıllık ortalama yağış 707.6 mm ve yıllık sıcaklık ortalama $14.6^{\circ} C^{\prime} \operatorname{dir}$ (MGM, 2019).

$$
\text { Çalışmada, Tarım İşletmeleri Genel }
$$
Müdürlüğü (TiGEM)'e ait Karacabey Tarım Işletmesi'ne ait detaylı toprak etüt ve haritalama raporu ve NASA'nın internet sitesinden indirilen $30 \mathrm{~m} \times 30 \mathrm{~m}$ çözünürlüklü DEM verisi materyal olarak kullanılmıştır. Etüt raporun ekinde basılı bulunan toprak haritası ArcGIS ortamında sayısallaştırılmıştır. MEDALUS'ta belirtildiği gibi çalışmada kullanılacak arazi karakteristikleri; ana materyal, tekstür, derinlik, eğim ve drenaj olarak belirlenmiştir. Bu parametreler MEDALUS metodolojisine göre yeniden sınıflandırmış ve yöntemde öngörülen sınır değerleri içinde yeniden değerlendirilmiştir. DEM verisi kullanılarak çalışma alanına ait yükseklik değerleri ve eğim sınıflarına ait haritalar oluşturulmuştur.

Kosmas ve ark. (1999) tarafından ileri sürülen metodoloji ve CBS metotları kullanılarak analizler gerçekleştirilmiştir. $\mathrm{Bu}$ amaçla arazi karakteristiklerine ait parametreler Çizelge 1'de sunulan değerler doğrultusunda skorlanmıştır. Skor cetvelinden elde edilen veriler kullanılarak her bir 
haritalama biriminde her bir parametre için haritalar üretilmiştir. Sonuç haritasının üretilmesi ve TKi'nin belirlenmesi için aşağıda algoritmadan faydalanılmıştır;
TKi $=($ Ana materyal $\mathrm{x}$ Tekstür $\mathrm{x}$ Derinlik $\mathrm{x}$ Drenaj $x$ Eğim) $)^{1 / 5} \quad$ Eşitlik (1)
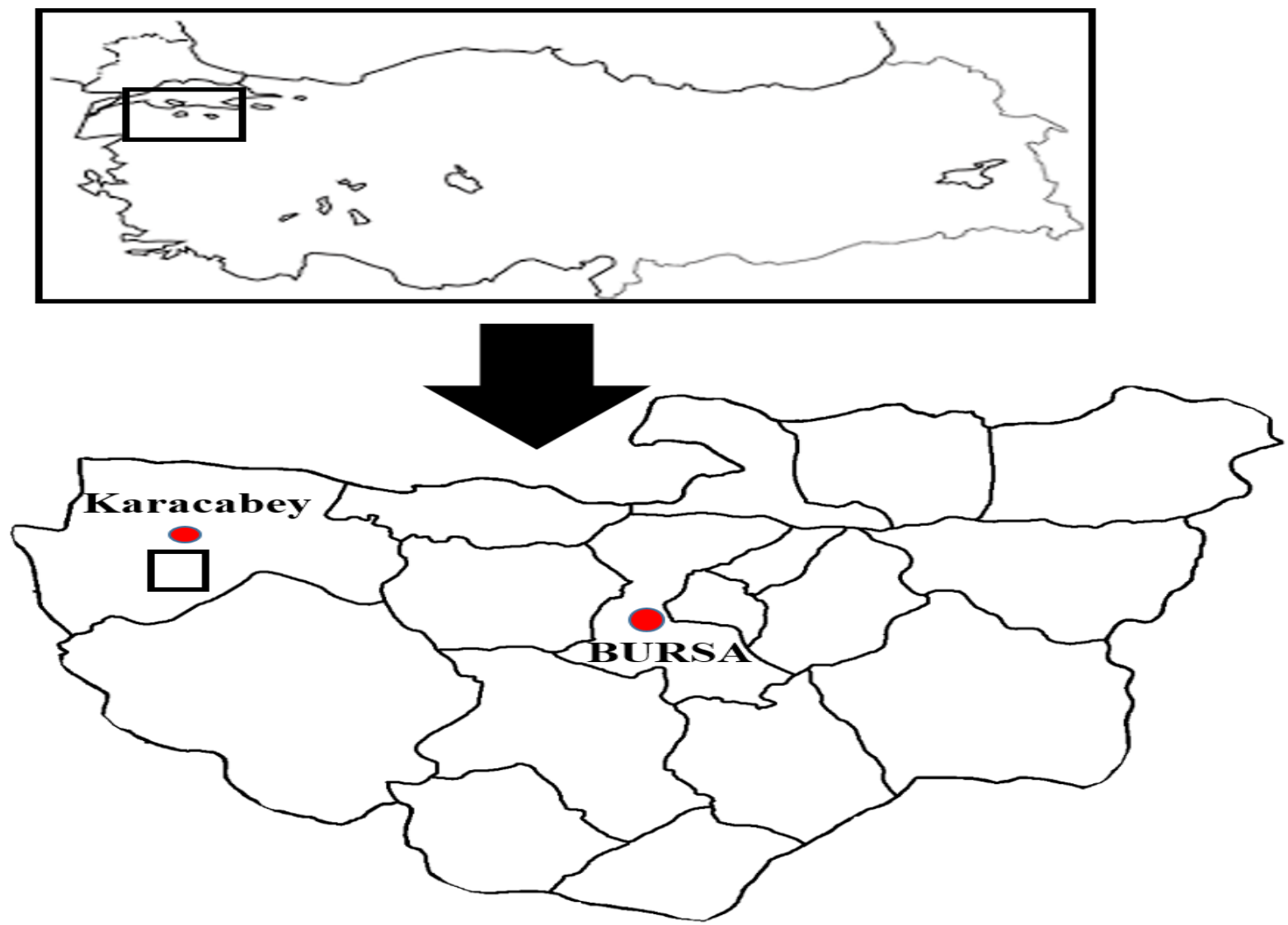

Şekil 1. Çalışma alanı.

Çizelge 1. MEDALUS tekstür, ana materyal, derinlik, eğim ve drenaj indeksi.

\begin{tabular}{cclcc}
\hline Alt parametreler & Sınıf & \multicolumn{1}{c}{ Değerlendirme } & Tanım & Ağırlık \\
\hline \multirow{4}{*}{ Tekstür } & 1 & İyi & L, SCL, SL, LS, CL & 1 \\
& 2 & Orta & SC, SiL, SiCL & 1.2 \\
& 3 & Zayıf & Si, C, SiC & 1.6 \\
& 4 & Oldukça zayıf & S & 2.0 \\
\hline \multirow{5}{*}{ Ana materyal } & 1 & İyi & Şeyl, şist, bazik, ultra bazik, konglomera, & 1.0 \\
& & & konsolide olmamış materyaller & \\
& 2 & Orta & Kireçtaşı, mermer, granit, riyolit, ignibrit, gnays, & 1.7 \\
& 3 & Zayıf & silttaşı, kumtaşı & 2.0 \\
\hline \multirow{5}{*}{ Derinlik (cm) } & 1 & Derin & Marn, piroklastikler & 1 \\
& 2 & Orta derin & $>75$ & 1.2 \\
& 3 & Sığ & $30-75$ & 1.6 \\
& 4 & Çok sığ & $15-30$ & 2.0 \\
\hline \multirow{5}{*}{ Eğim (\%) } & 1 & Hafif eğimli ve düz & $<6$ & 1.0 \\
& 2 & Hafif eğimli & $6-18$ & 1.2 \\
& 3 & Dik eğimli & $18-35$ & 1.5 \\
& 4 & Çok dik eğimli & $>35$ & 2.0 \\
\hline \multirow{2}{*}{ Drenaj } & 1 & İyi drenajlı & & 1.0 \\
& 2 & Bozuk drenajlı & & 1.2 \\
& 3 & Zayıf drenajlı & & 2.0 \\
\hline
\end{tabular}


Elde edilen değerler MS Excel paket programında hesaplanmış ve manuel olarak

\section{Bulgular ve Tartışma}

MEDALUS metodolojisine göre TKI'nin belirlenmesi için çalışmada ana materyal, toprak tekstürü, toprak derinliği, drenaj durumu ve eğim indikatörleri için ayrı ayrı hesaplamalar yapılmış ve haritalar üretilmiştir. Yapılan bütün hesaplamalar sonucu elde edilen veriler haritalama birimlerine atanarak sonuç haritası üretilmiştir.

MEDALUS metodolojisine göre yapılan değerlendirme ve hesaplamalar sonucu oluşturulan veriler Çizelge 2'de sunulmuştur. İlgili çizelge verileri incelendiğinde çalışma alanı topraklarının \%23.78'i tekstürel açıdan iyi olarak sınıflandırılırken, \%31.93'ü orta, \%39.04'ü zayıf ve \%5.25'i oldukça oluşturulan TKI öznitelik tablosuna aktarılarak Karacabey Tarım İşletmesine ait TKi belirlenmiştir.

zayıf olarak sınıflandırılmıştır (Şekil 2). Yapılan sınıflandırmada orta bünyeli topraklar en iyi sınıf içinde sınıflandırılırken kaba bünyeli topraklar ise en zayıf olarak sınıflandırılmıştır. Orta-ince ve ince tekstürlü topraklarda bu iki sınıf arasında değişen derecelerde sınıflandırılmıştır. Tekstür grupları sınıflandırılırken toprakların su tutma kapasiteleri ve yarayışlı su (RAM) miktarları dikkate alınmıştır. İlaveten, tekstür FAO sınıflamasındaki ince, orta ve kaba tekstür gruplamasına göre de değerlendirilmiştir. Aynı sınıflandırmayı kendi yürüttüğü çalışmada da uygulayan Bayramin (2003) Beypazarı Tarım İşletmesi Topraklarının tekstürel açıdan \%17.9'unun iyi, \%27.9'unun orta, \%49.5'inin zayıf ve \%4.60'ının çok zayıf olduğunu belirlemiştir.

Çizelge 2. MEDALUS yöntemine göre çeşitli parametrelere ait değerlendirme sonuçları.

\begin{tabular}{|c|c|c|c|c|c|}
\hline Alt parametreler & Sinif & Tanım & & Alan (ha) & Oran (\%) \\
\hline \multirow{5}{*}{ Tekstür } & 1 & İyi & & 24142.65 & 23.78 \\
\hline & 2 & Orta & & 32416.93 & 31.93 \\
\hline & 3 & Zayıf & & 39635.36 & 39.04 \\
\hline & 4 & Oldukça zayıf & & 5330.06 & 5.25 \\
\hline & & & Toplam & 101525.00 & 100 \\
\hline \multirow{3}{*}{ Ana materyal } & 1 & İyi & & 60610.42 & 59.70 \\
\hline & 2 & Orta & & 40914.58 & 40.30 \\
\hline & & & Toplam & 101525.00 & 100 \\
\hline \multirow{5}{*}{ Derinlik (cm) } & 1 & Derin & & 76011.77 & 74.87 \\
\hline & 2 & Orta derin & & 5370.67 & 5.29 \\
\hline & 3 & Siğ & & 15685.61 & 15.45 \\
\hline & 4 & Çok sığ & & 4457.56 & 4.39 \\
\hline & & & Toplam & 101525.00 & 100 \\
\hline \multirow{4}{*}{ Eğim (\%) } & 1 & Hafif eğimli ve düz & & 79504.23 & 78.31 \\
\hline & 2 & Hafif eğimli & & 17005.44 & 16.75 \\
\hline & 3 & Dik eğimli & & 5015.33 & 4.94 \\
\hline & & & Toplam & 101525.00 & 100 \\
\hline \multirow{4}{*}{ Drenaj } & 1 & İyi drenajlı & & 60397.22 & 59.49 \\
\hline & 2 & Bozuk drenajlı & & 16213.54 & 15.97 \\
\hline & 3 & Zayıf drenajlı & & 24914.24 & 24.53 \\
\hline & & & Toplam & 101525.00 & 100 \\
\hline
\end{tabular}

Ana materyaller çölleşmeye duyarlılık açısından üç sınıfta gruplandırılmaktadır (Kosmas ve ark., 1999). Çalışma alanı arazileri, ana materyallerine göre iki sınıf içinde değerlendirilmiştir (Şekil 3). Bu gruplamaya göre ana materyaller açısından çalışma alanının \%59.70 iyi ve \% 40.30'u ise orta olarak sınıflandırılmıştır.

Toprak derinliği yüzeyden ana kayaya kadar ya da biyolojik aktivitenin son bulduğu noktaya kadar olan derinliği ifade etmektedir (Brady ve Weil, 1999). Toprak derinliği bitkilerin sağlıklı bir kök gelişimi sağlaması ve su ile bitki besin maddesinden faydalanmasına olanak sağlayan önemli bir parametredir. Toprak derinliği dört sınıfa ayrılarak hesaplanmıştır (Şekil 4). Yapılan hesaplamalar sonucunda, çalışma alanı topraklarının \%74.87'i derin, \%5.29'u orta derin, \%15.45'i sığ ve \%4.39'u çok sığ olarak sınıflandırılmıştır.

Eğimin toprak erozyonu üzerindeki etkisi düşünülerek üç sınıfta gruplandırılmıştır. Yapılan değerlendirme sonucunda çalışma alanı topraklarının \%78.31'i düz-hafif eğimli, \%16.75'i hafif eğimli ve \%4.94'ü dik eğimli olarak sınıflandırılmıştır (Şekil 5). Toprak eğim sınıfları arttıkça toprakların kalite sınıflarında azalma meydana gelmekte ve duyarlılıkları da artmaktadır. 
Aksoy (2016)'nın gerçekleştirdiği araştırmada; çalışma sahasının \%43.60'ının dik ve \%46.99'unun ise çok dik arazilerden meydana geldiğini belirtmiş ve erozyona duyarlı alanların toprak kalite sınıflarının düşük olduğunu bildirmiştir.

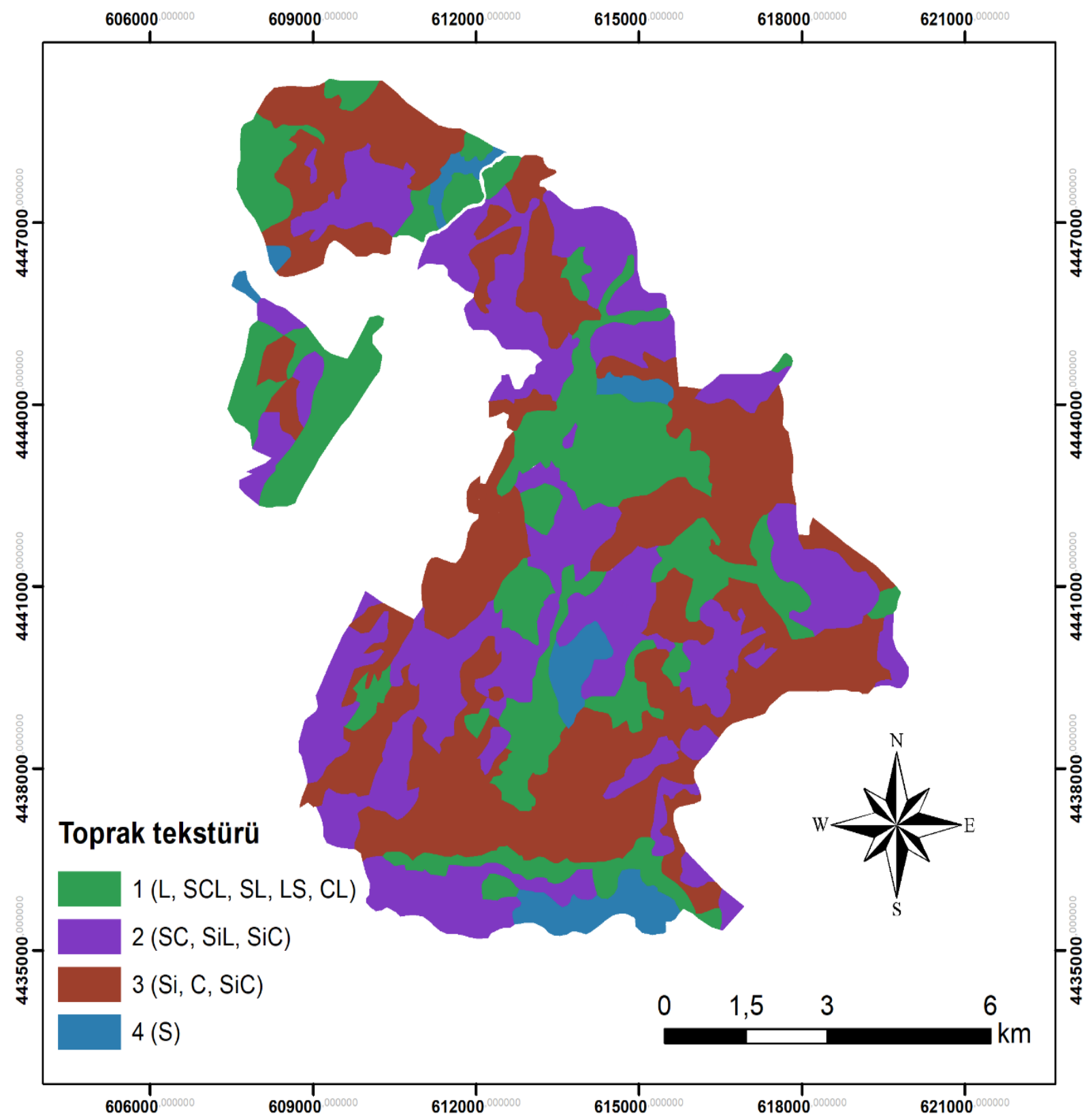

Şekil 2. Tekstür grupları.

Aynı şekilde Everest ve ark. (2017)'de yürüttüğü çalışmada Troya'da ki dik ve çok dik arazilerin erozyona çok duyarlı olduğunu bildirmişlerdir. 


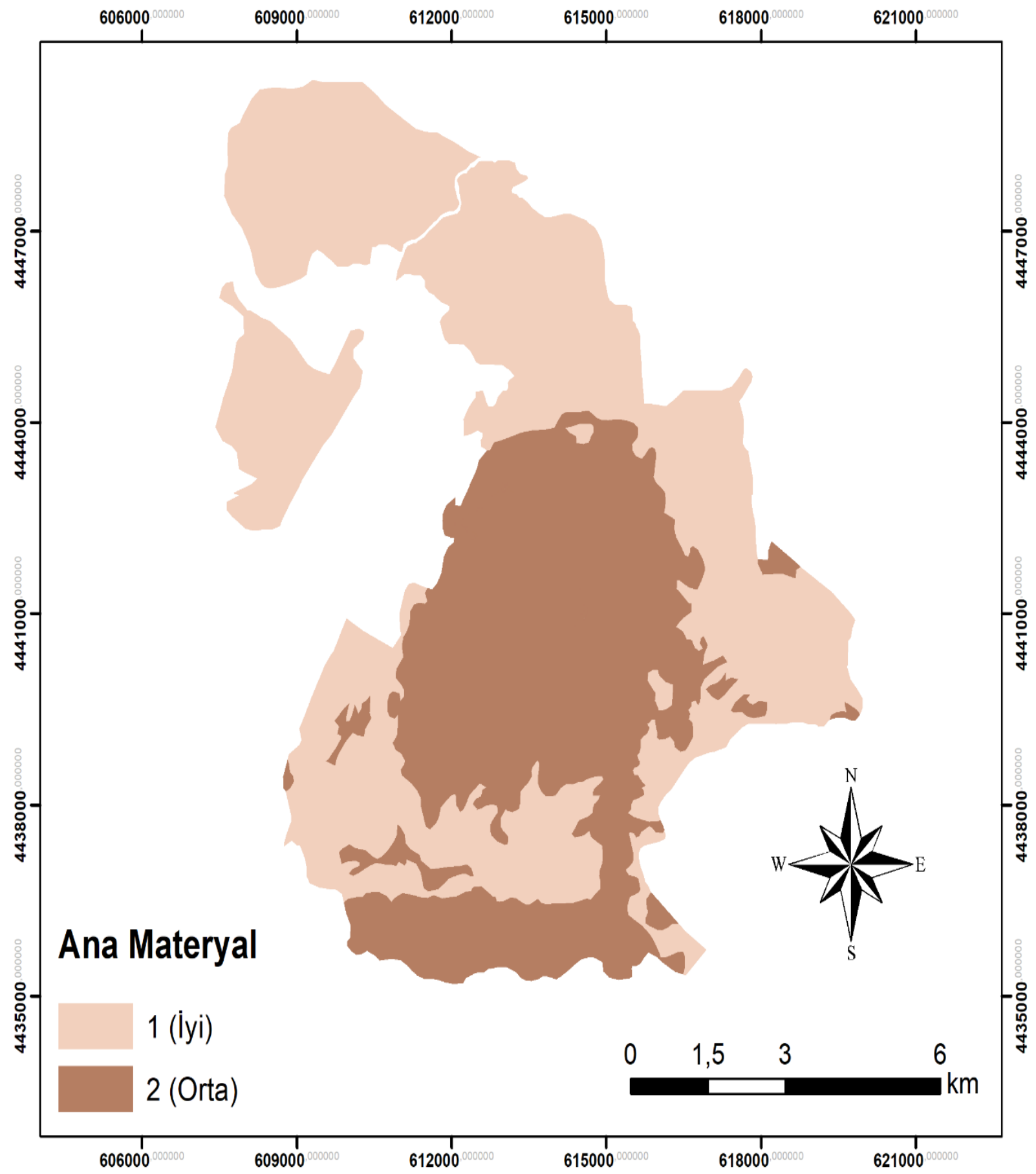

Şekil 3. Ana materyal sınıflandırması. 


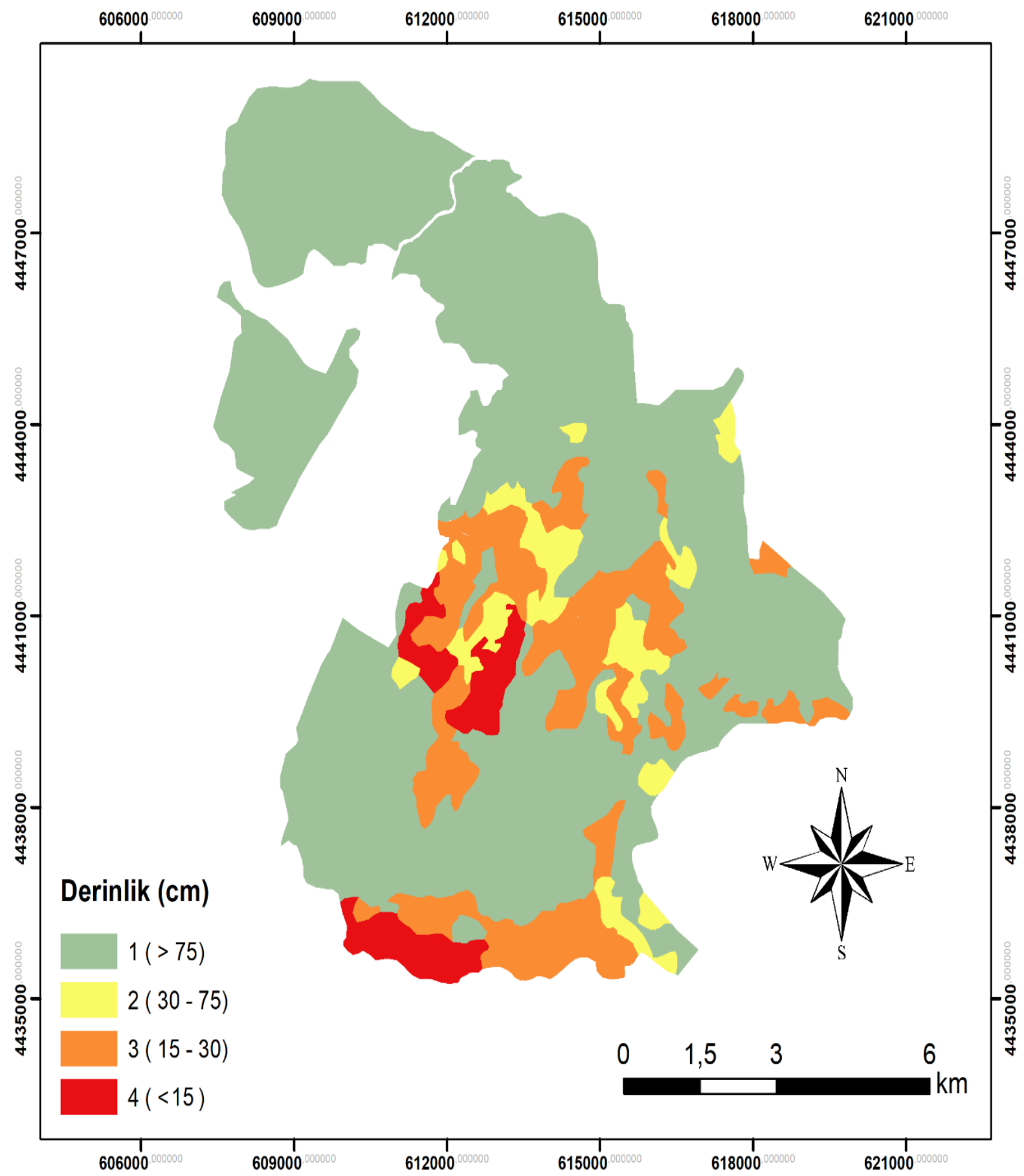

Şekil 4. Derinlik haritası. 


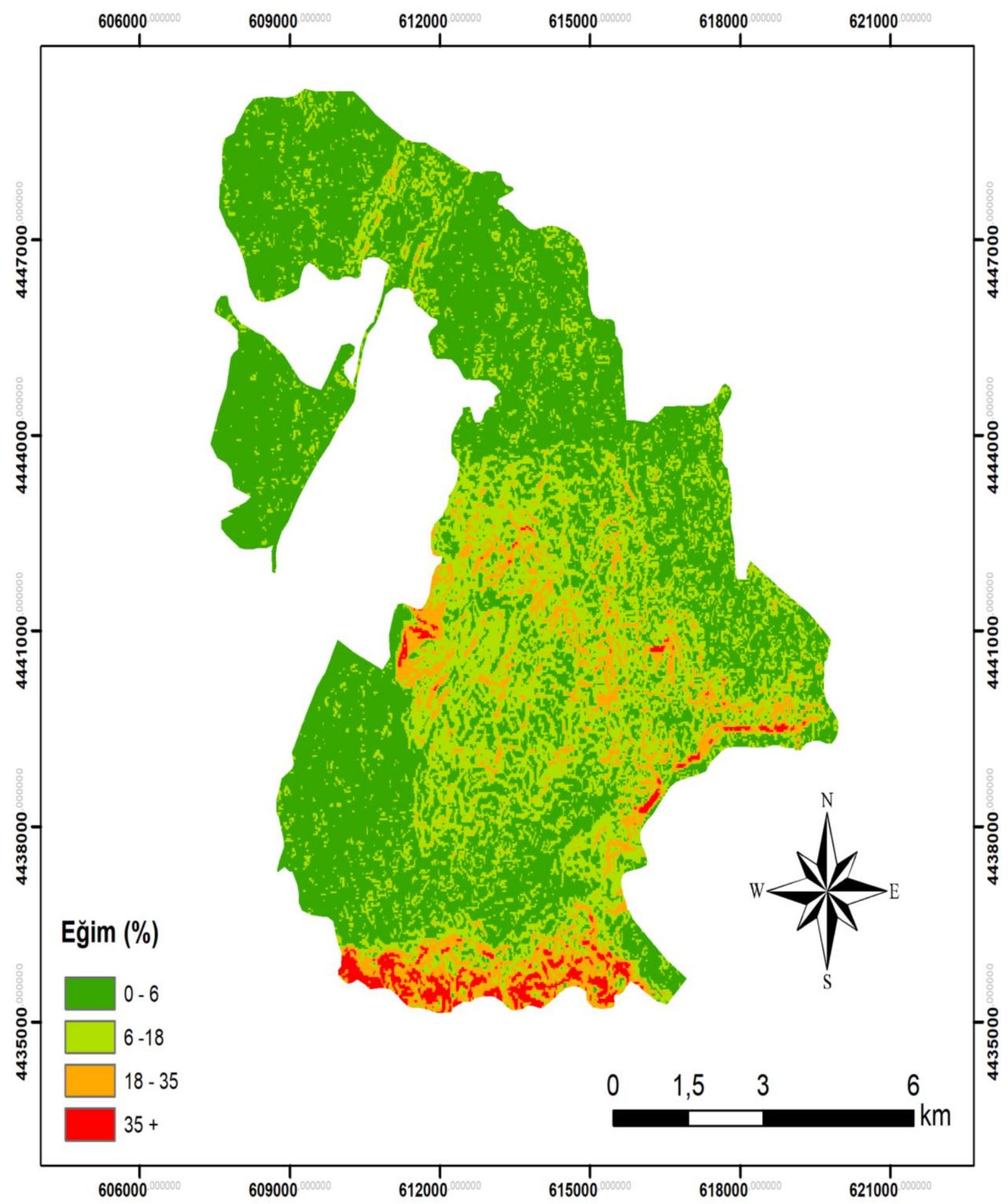

Şekil 5. Eğim haritası. 


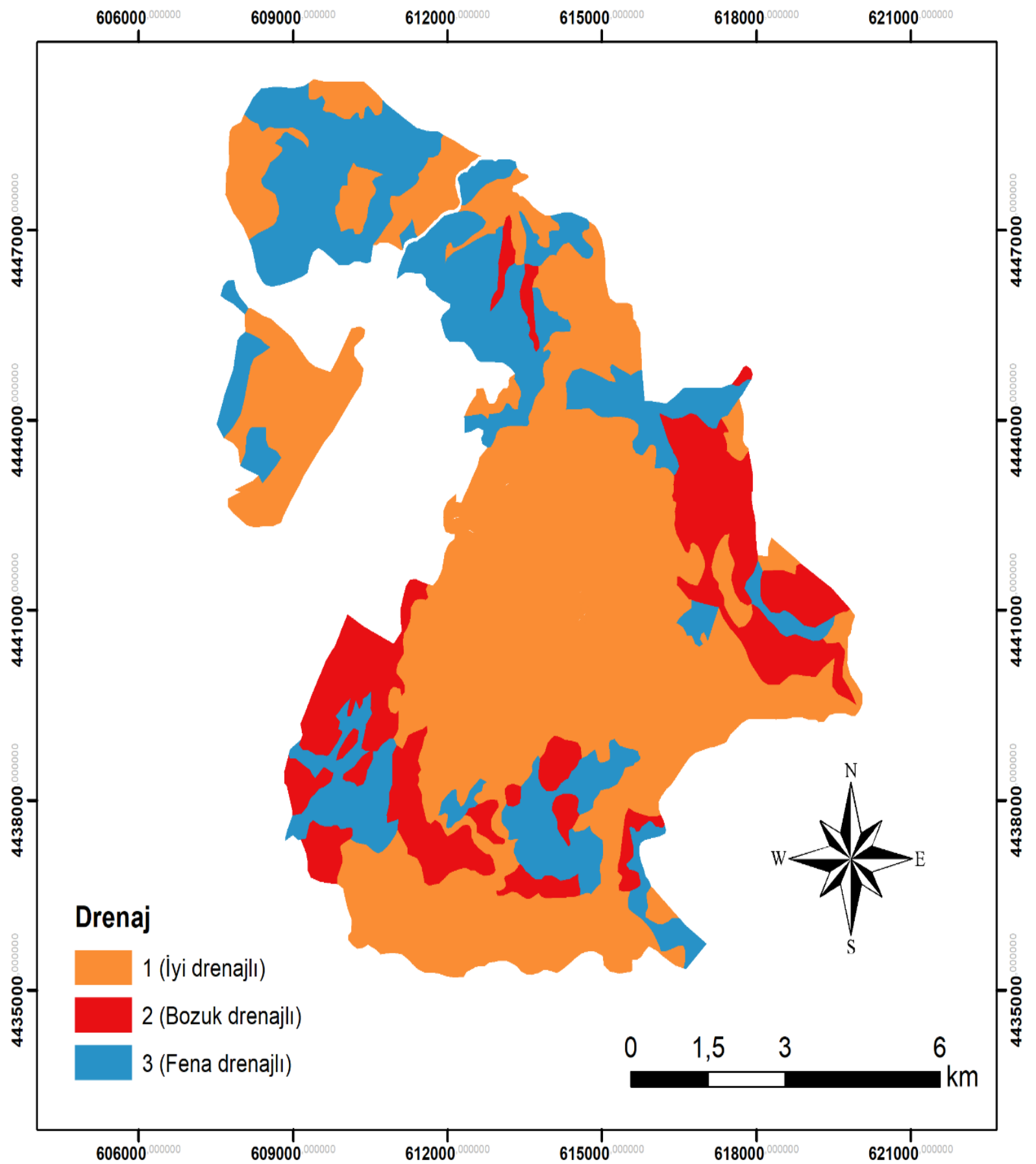

Şekil 6. Drenaj haritası.

Drenaj durumu üç kategori içinde değerlendirilmiştir. Buna göre çalışma alanı topraklarının \%8.28'i iyi drenajlı, \%49.17'si orta drenajlı ve $\% 42.55^{\prime} \mathrm{i}$ zayıf drenajlı olarak sınıflandırılmıştır (Şekil 6).

Oluşturulan ana materyal, toprak tekstürü, derinlik, drenaj ve eğim haritalarının öz nitelik tablosundaki değerler Eşitlik 1'deki algoritma kullanılarak hesaplanmış ve poligon bazında sonuç haritası üretilmiştir. $\mathrm{Bu}$ veri seti MEDALUS metodolojisinde bulunan bileşenlerden biri olan toprak kalite indeksi sınıflarına göre yeniden sınıflandııımış ve Karacabey tarım işletmesine ait toprak kalite indeksi belirlenmiştir. Bu veriler ışı̆̆ında Karacabey tarım işletmesi topraklarının $\% 8.28$ 'i iyi, \%49.17'si orta ve \%42.55'i zayıf olarak sınıflandırılmıştır (Şekil 7 ve Çizelge 3). Diğer bir ifade ile arazilerin \%42.55'inde arazilerin duyarlılı̆ının çok yüksek olduğu görülmektedir. TKi sonuç haritası incelendiğinde çalışma alanının merkezinde ve güneyinde bulunan yüksek ve eğimli arazilerin genel olarak hassas ve sorunlu oldukları görülmektedir. Bu bölümlerde özellikle majör problem eğim ve derinliktir. 
Çizelge 3. Karacabey işletmesi arazisi TKi sınıflandırması.

\begin{tabular}{ccccc}
\hline Sınıf & Aralık & Tanım & Alan (ha) & Oran (\%) \\
\hline 1 & $<1.13$ & Yüksek kaliteli & 8406.27 & 8.28 \\
2 & $1.13-1.45$ & Orta kaliteli & 49919.84 & 49.17 \\
3 & $>1.45$ & Düşük kaliteli & 43198.89 & 42.55 \\
& & Toplam & 101525.00 & 100 \\
\hline
\end{tabular}

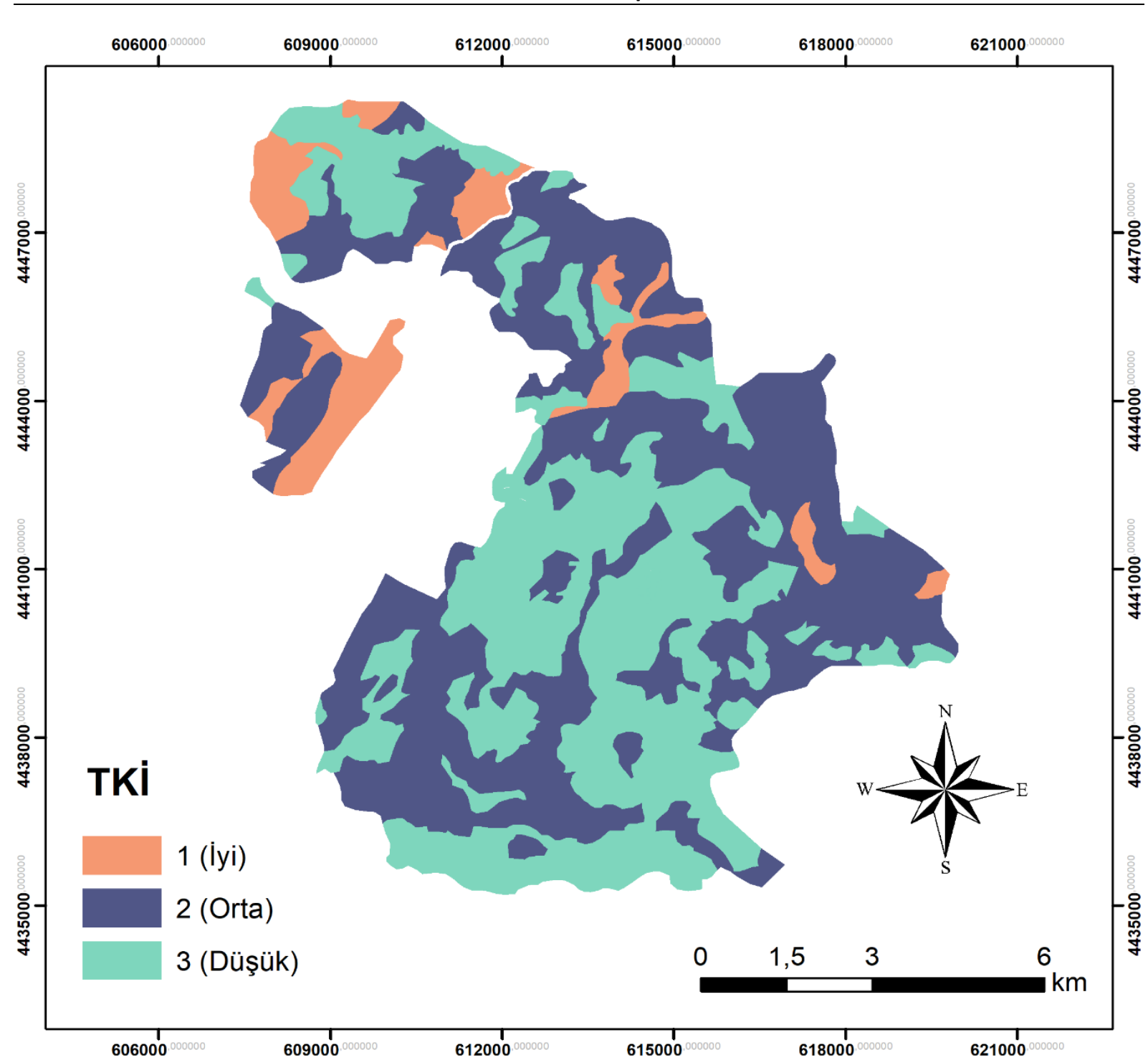

Şekil 7. Karacabey Tarım İşletmesi Toprak Kalite İndeksi.

\section{Sonuç ve Öneriler}

Bu çalışma ile Bursa ili sınırları içinde Bulunan Karacabey Tarım İşletmesi arazilerinin toprak kalite indeks sonuçlarının yorumlanması ile arazi bozulumu ve çölleşme açısından kalite sınıfları belirlenmiştir. Daha önceden hazırlanmış seri düzeyinde detaylı toprak haritaları, analiz sonuçları ve $30 \mathrm{~m} \times 30 \mathrm{~m}$ çözünürlüklü uydu verisinden sağlanan yükseklik verileri (DEM) kullanılarak tarım işletmesi arazilerine ait arazi karakteristiklerinin mevcut durumu tanımlanmış ve metodolojide belirtilen kriterlere göre sayısallaştırılmıştır. Arazi karakteristiklerine ait her bir haritalama birimindeki sayısal değerler bir eşitlik yardımı ile çarpılarak toprak kalite indeksleri (TKi) hesaplanmıştır. Poligon bazlı sayısallaştırılmış toprak haritalarında her poligona (haritalama birimine) ait TKi verileri CBS ortamında veri tabanına aktarılmıştır. CBS veri tabanında her bir arazi karakteristiğine ait dağılım haritaları üretilmiştir. Arazi karakteristiklerine ait TKi verileri kullanılarak toprak kalite indeksi haritası oluşturulmuştur. Kullanılan MEDASLUS metodolojisine göre tarım işletmesi arazilerinin \%8.28'i iyi, \%49.17'si orta ve \%42.55'i zayıf olarak sınıflandırılmıştır. Çalışma alanındaki yüksek araziler (Şekil 8) eğim, derinlik ve ana materyal gruplamasında da orta ve zayıf sınıfta yer almışlardır. Bu alanlar tüm arazi karakteristiklerinin 
birlikte değerlendirilmesi (formülasyon) sonucu TKi sınıflamasında da en hassas alanlar olarak tanımlanmışlardır. Çalışma alanındaki en kaliteli araziler ise; derinlik problemi olmayan, düz ve düze yakın eğimli, su tutma kapasitesi ve geçirgenliği optimal düzeyde olan, ana materyalce daha iyi sınıfta yer alan sorunsuz veya minimum düzeyde problem içeren arazilerdir.

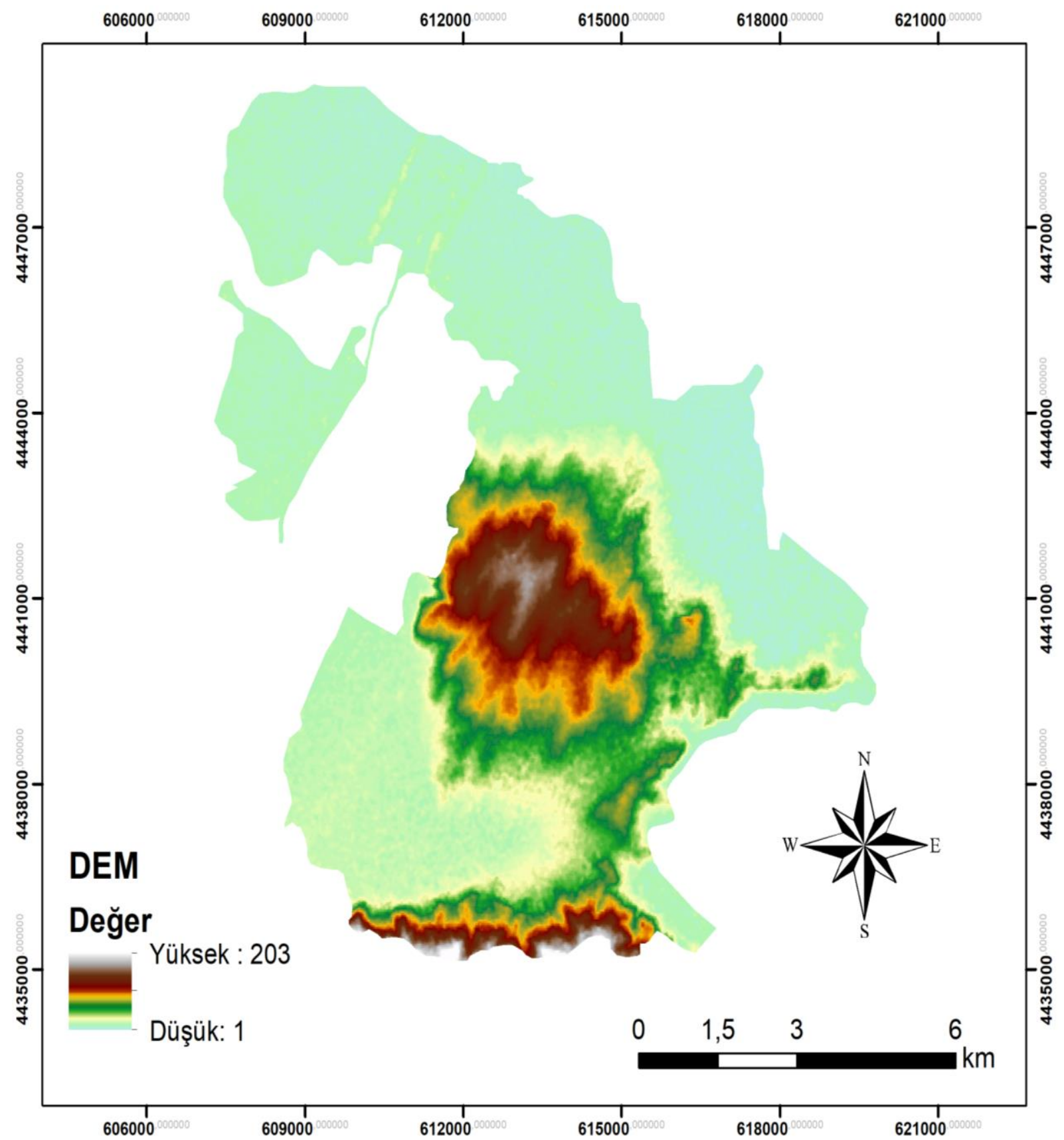

Şekil 8. Çalışma alanı yükseklik haritası.

Küresel ısınma nedeniyle yaşanan iklim değişiklikleri ve mevsimsel farklılaşmaların etkisi giderek artmaktadır. Akdeniz ikliminin yaşandığı bölgelere uyarlanmış olan MEDALUS modeli ile degrade olmaya hassas olan alanların tespit edilmesi arazi kullanım planlarının oluşturulması ve gelecek projeksiyonların uygulanabilmesi açısından çok önemli veriler sunmaktadır. Bu veriler, hem karar vericiler ve hem de uygulayıcılar açısından sürdürülebilir bir toprak yönetimi ve ekosistem devamlılığı yönünden çok önemli olduğu düşünülmektedir. Bu çalışma ile üretilen haritalar ile karar vericilerin ve uygulayıcıların politika oluşturmalarına, planlamalar ve desteklemede öncelikler hakkında fikir sahibi olmalarına yardımcı olabileceği düşünülmektedir. Bu türde çalışmaların ülke genelinde yaygınlaşması ve faklı bölgeler için uygulanması, Türkiye ölçeğinde hassas alanların belirlenmesine yardımcı olabilecektir. 


\section{Kaynaklar}

Aksoy, B. R. 2016. MEDALUS modeli ile arazi degradasyonu ve çölleşme riskinin belirlenmesi örnek çalışma; İnebolu Havzası, Ondokuz Mayıs Üniversitesi, FBE, Yüksek Lisans Tezi.

Bayramin, i. 2003. Beypazari topraklarinin MEDALUS metoduna göre toprak kalite indekslerinin belirlenmesi. Harran. Üniversitesi. Z.F.Dergisi, 7 (3-4):29-35.

Benabderrahmane, M.C., Chenchouni, H. 2010. Assessing environmental sensitivity areas to desertification in Eastern Algeria using Mediterranean desertification and land use "MEDALUS" model. Int J Sustain Water Environ Syst, 1(1), 5-10.

Brady, N.C., Weil, R.R. 1999. The nature and properties of soil 12th ed. Mac. Pub. Com. New York, 625-640.

Budak, M., Günal, H., Çelik, İ., Yıldız, H., Acir, N., Acar, M. 2018. Environmental sensitivity to desertification in northern Mesopotamia; application of modified MEDALUS by using analytical hierarchy process. Arabian Journal of Geosciences, 11(17), 481.

Contador, J.L., Schnabel, S., Gutiérrez, A.G., Fernández, M.P. 2009. Mapping sensitivity to land degradation in Extremadura. SW Spain. Land Degradation \& Development, 20(2), 129-144.

De Paola, F., Ducci, D., Giugni, M. 2013. Desertification and erosion sensitivity. A case study in southern Italy: the Tusciano River catchment. Environmental earth sciences, 70(5), 2179-2190.

Dengiz, O., Özden, Ş., Başkan, O., Özcan, H. 2004. Determination Of Soil Quality Index Of Bala Statefarm Soils According To The Medalus Methodology, International Soil Congress on
Natural Resource Management for Sustainable Development. 7-10 June 2004, Erzurum-Turkey.

Everest, T., Tasli, T.C., Akbulak, C., Sungur, A. 2017. Ecological risk assessment for protected areas: case of Troia historical national park, Canakkale-Turkey. FEB-Fresenius Environmental Bulletin, 26, 7463-7472.

Everest, T. 2018. Prioritization of Karamenderes basin's groundwater potential with morphometric analyses (in semi-arid climatic conditions Çanakkale, Turkey). Fresenius Environmental Bulletin, 27(12), 8253-8263.

Kosmas, C., Kirkby, M.J., Geeson, N. (Eds.). 1999. The Medalus Project: Mediterranean desertification and land use: Manual on key indicators of desertification and mapping environmentally sensitive areas to desertification. Directorate-General Science, Research and Development. 88p.

Lahlaoi, H., Rhinane, H., Hilali, A., Lahssini, S., Moukrim, S. 2017. Desertification assessment using MEDALUS model in watershed Oued El Maleh, Morocco. Geosciences, 7(3), 50.

MGM. 2019. Devlet Meteoroloji İşleri Genel Müdürlüğü, Resmi İstatistikler.

Salvati, L., Zitti, M. 2005. Land degradation in the Mediterranean basin: Linking biophysical and economic factors into an ecological perspective. Biota International Journal of Biology and Ecology. 5, 67- 77.

Sepehr, A., Hassanli, A.M., Ekhtesasi, M.R., Jamali, J.B. 2007. Quantitative assessment of desertification in south of Iran using MEDALUS method. Environmental monitoring and Assessment, 134(1-3), 243.

TigEM. 1988. Karacabey Tarım İşletmesi Topraklarının Etüd ve Haritalaması. 86s. 